\title{
MEDIA PEMBELAJARAN INTERAKTIF LECTORA INSPIRE SEBAGAI INOVASI PEMBELAJARAN
}

\author{
Norma Dewi Shalikhah, Ardhin Primadewi, Muis Sad Iman \\ Universitas Muhammadiyah Magelang \\ Email: normadewi75@yahoo.co.id \\ HP. 085643848777
}

\begin{abstract}
The utilization of information and communication technology in education sector is a tremendous output. Support of ICT is hoped to become an innovation in learning with many involving information technology components inside. Therefore, in globalization era, education sector can not pass from its extent, with involves the inherent technology can produce a system of education. This paper discusses the interactive learning media that involve education technology using lectora inspire application. Lectora inspire is designed specifically for the beginner with purpose user friendly to use to make learning media, and can make the material test or evaluation. The development of interactive learning media with lectora inspire is conducted with how to provide training to the teachers in the elementary school. The methods are done with phases, includes gathering information, planning tools, implementing, presenting and reflecting. The object of this training is MIM Jagalan and MIM Jumoyo Greeting sub Magelang regency.
\end{abstract}

Keywords: Media Interactive Learning, Lectora Inspire, Learning Innovation

\begin{abstract}
Abstrak
Pemanfaatan teknologi informasi dan komunikasi dalam dunia pendidikan merupakan satu terobosan yang luar biasa. Dukungan TIK ini diharapkan dapat menjadi suatu inovasi dalam pembelajaran dengan banyak melibatkan komponenkomponen teknologi informasi didalamnya. Oleh karena itu dalam era globalisasi, sektor pendidikan pun tak luput dari jangkauannya, yaitu dengan melibatkan teknologi didalamnya dapat menghasilkan suatu sistem pendidikan. Dalam tulisan ini dibahas mengenai media pembelajaran interaktif yang melibatkan teknologi pendidikan dengan memanfaatkan aplikasi lectora inspire. Lectora inspire didesain khusus bagi pemula sehingga keunggulan dari lectora inspire sangat mudah digunakan dalam pembuatan media pembelajaran dan dapat membuat materi uji atau evaluasi. Pengembangan media pembelajaran interaktif dengan lectora inspire ini, dilaksanakan dengan cara memberikan pelatihan kepada guru-guru di madrasah ibtidaiyah. Metode yang dilakukan tahapannya meliputi mengumpulkan informasi, perencaaan, pelaksanaan, presentasi, dan refleksi. Objek dari pelatihan ini adalah MIM Jagalan dan MIM Jumoyo Kecamatan Salam Kabupaten Magelang.
\end{abstract}

Kata kunci: Media Pembelajaran Interaktif, Lectora Inspire, Inovasi Pembelajaran 


\section{Pendahuluan}

Seiring perkembangan teknologi dan informasi yang semakin pesat, cenderung akan mempengaruhi segenap kehidupan sosial, ekonomi, politik, budaya, serta pendidikan dan pelatihan. Dalam bidang pendidikan, inovasi adalah hal yang mutlak dilakukan, karena tanpa inovasi akan terjadi ketertinggalan pada dunia pendidikan kemudian akan berimbas pada elemenelemen kehidupan yang lain seperti politik, ekonomi, sosial dan lain-lain.

Suatu perubahan, termasuk perubahan di bidang pendidikan dapat dikatakan sebagai bentuk inovasi apabila perubahan tersebut dilakukan dengan sengaja dan untuk memperbaiki kondisi sebelumnya agar lebih menguntungkan demi meningkatkan kehidupan yang lebih baik.

Oleh sebab itu, inovasi pada dasarnya merupakan ide cemerlang yang memunculkan hal baru seperti praktik-praktik tertentu, produk dari suatu hasil olah pikir dan olah teknologi yang diterapkan melalui tahapan tertentu untuk memecahkan persoalan yang timbul dan memperbaiki suatu keadaan tertentu atau proses tertentu yang terjadi di masyarakat. Dalam bidang pendidikan misalnya, untuk memecahkan persoalanpersoalan yang dihadapi, telah banyak contoh model-model inovasi dalam berbagai bidang seperti usaha pemerataan pendidikan, peningkatan mutu, peningkatan efektifitas dan efisiensi pendidikan, dan relevansi pendidikan.

Dalam dunia pendidikan, metode pembelajaran kini semakin berkembang. Inovasi yang berbentuk metode dapat berdampak pada perbaikan sistem pembelajaran dan meningkatkan kualitas atau mutu pendidikan. Dengan demikian, metode baru atau cara baru dalam melaksanakan proses pembelajaran dapat menjadi suatu upaya meningkatkan efektivitas pembelajaran. Sementara itu, inovasi dalam teknologi juga perlu diperhatikan mengingat banyak produk dari hasil teknologi dapat dipergunakan untuk meningkatkan kualitas pendidikan, seperti penggunaannya untuk teknologi pembelajaran, serta pengelolaan informasi pendidikan.

Trianto (2010:17) mengatakan bahwa pembelajaran merupakan aspek kegiatan manusia yang kompleks, yang tidak sepenuhnya dapat dijelaskan. Pembelajaran secara sederhana dapat diartikan sebagai produk interaksi berkesinambungan antara pengembangan dan pengalaman hidup. Sedangkan pembelajaran dalam makna kompleks adalah usaha sadar dari seorang guru untuk membelajarkan siswanya yaitu mengarahkan interaksi siswa dengan sumber belajar lainnya untuk mencapai tujuan yang diharapkan.

Ditemukan beberapa guru masih menggunakan metode ceramah dalam proses pembelajaran. Para guru jarang sekali menggunakan media pembelajaran khususnya media pembelajaran berbasis IT dan belum bisa membuat media pembelajaran interaktif dikarenakan belum ada sosialisasi tentang peningkatan keterampilan dan kreativitas guru melalui pengembangan media pembelajaran interaktif. Guru dituntut untuk dapat mengembangkan keterampilan membuat media pembelajaran, apalagi media tersebut belum tersedia di madrasah. Untuk itu, guru harus memiliki pengetahuan dan pemahaman yang cukup tentang media pembelajaran.

Dewasa ini, telah berkembang pesat produk multimedia seiring berkembangnya ilmu teknologi dan komunikasi. Mulai dari komputer, telepon, serta alat komunikasi lainnya. Hal ini sangat berpengaruh pada perkembangan penggunaan multimedia dalam pembelajaran di sekolah. Jika para guru tidak mengikuti perkembangan multimedia ini, pasti akan ketinggalan dengan perkembangan masyarakat. Pesan pembelajaran pun menjadi tidak tuntas karena media yang digunakan kurang lengkap. Kondisi ini masih banyak terjadi di sekolah-sekolah terutama di sekolah pelosok. Untuk itu, guru dituntut bisa menerapkan media pembelajaran lebih dari satu jenis. Sebab pembelajaran yang menggunakan multimedia dapat lebih efektif dan efisien 
serta bisa meningkatkan hasil belajar siswa.

Kemampuan dan keterampilan guru menjadi kunci utama dalam pembelajaran multimedia ini. Pembelajaran multimedia ini, menuntut guru lebih menguasai teknologi. Misalnya, saat ini guru bisa menggunakan laptop yang di dalamnya telah terangkai komponen-komponen berbasis multimedia. Ada visualisasi gambar, audio, video, wireless program, serta software lain yang bisa digunakan dalam pembelajaran. Namun, jika guru tidak bisa mengoperasionalkan kecanggihan teknologi ini pasti sulit mewujudkan pembelajaran berbasis multimedia. Sehingga perlu adanya pelatihan bagi para guru untuk dapat mengembangkan media pembelajaran berbasis multimedia. Disinilah kami memberikan pelatihan kepada para guru untuk mampu menciptakan pembelajaran yang inovatif dan lebih menarik, yaitu salah satunya dengan membuat media pembelajaran interaktif dengan lectora inspire.

Lectora inspire merupakan program yang efektif dalam membuat media pembelajaran. Lectora inspire merupakan software pengembangan belajar elektronik (e-learning) yang relatif mudah diaplikasikan atau diterapkan karena tidak memerlukan pemahaman bahasa pemrograman yang canggih. Karena Lectora inspire memiliki antarmuka yang familiar dengan kita yang telah mengenal maupun menguasai Microsoft Office. (Muhammad Mas'ud, 2012:3).

Dengan menggunakam lectora inspire, materi pelajaran didesain semenarik mungkin, dapat menampilkan video, serta gambar-gambar animasi yang berhubungan dengan materi pelajaran agar peserta didik lebih memperhatikan apa yang disampaikan oleh guru. Proses pembelajaran akan lebih menyenangkan dan bermakna, sehingga berpengaruh pada peningkatan prestasi belajar peserta didik.

\section{Media Pembelajaran}

Media secara harfiah berarti tengah, pengantar, atau perantara. Association of Education and Communication Technologi
(AECT) memberikan definisi media sebagai bahan dan peralatan yang tersedia untuk menyampaikan pesan tertentu. Pendapat lain dikemukakan oleh Trini Prastati (2005:3) memberi makna media sebagai segala sesuatu yang dapat memberikan informasi dari sumber informasi ke penerima informasi.

Sedangkan Sutirman (2013:15) menyatakan bahwa media pembelajaran dikatakan sebagai alat-alat grafis, photografis atau elektronis, yang dapat digunakan untuk menangkap, memproses, dan menyusun kembali informasi visual atau verbal. Jadi media pembelajaran adalah segala sesuatu yang dapat menyalurkan pesan, dapat merangsang pikiran, perasaan, perhatian, dan minat siswa, sehingga dapat mendorong terciptanya proses belajar pada diri siswa.

Media pembelajaran berkembang dari waktu ke waktu, seiring dengan perkembangan teknologi. Perkembangan media pembelajaran juga mengikuti tuntutan dan kebutuhan pembelajaran. Beberapa ahli menggolongkan beberapa macam media, seperti Bretz membagi media menjadi tiga macam yaitu media yang dapat dilihat (video), media yang dapat didengar (audio), dan media yang dapat bergerak. Media visual dikelompokkan lagi menjadi tiga yaitu gambar visual, grafis, dan simbol verbal. (Trini Prastati, 2005:9).

\section{Azhar Arsyad}

mengelompokkan media pembelajaran menjadi empat macam, yaitu media cetak, media hasil teknologi audio visual, media hasil teknologi komputer, dan media hasil gabungan teknologi cetak dan komputer.

Levie \& Lents sebagaimana dikutip oleh Azhar Arsyad (2007:16) mengemukakan empat fungsi media pembelajaran, khususnya media visual, yaitu fungsi atensi, fungsi afektif, fungsi kognitif, dan fungsi kompensatoris. Fungsi atensi yaitu menarik dan mengarahkan perhatian siswa untuk berkonsentrasi kepada isi pelajaran yang berkaitan dengan visual yang ditampilkan atau bisa berupa teks materi pelajaran. Media gambar atau animasi yang ditampilkan melalui LCD dapat memfokuskan perhatian 
mereka kepada pelajaran yang akan mereka terima. Fungsi afektif yaitu dapat terlihat dari keterlibatan emosi dan sikap siswa pada saat menyimak tayangan materi pelajaran yang disertai dengan visualisasi. Fungsi kognitif terlihat dari kajian-kajian ilmiah yang mengemukakan bahwa lambang visual bertujuan untuk memahami dan mengingat informasi atau pesan yang terkandung dalam gambar. Sedangkan, fungsi kompensatoris dari media pembelajaran adalah membantu pemahaman dan ingatan isi materi bagi siswa yang lemah dalam membaca.

Media pembelajaran yang baik harus memenuhi beberapa syarat. Media pembelajaran harus meningkatkan motivasi siswa. Selain itu, media juga harus merangsang siswa mengingat apa yang sudah dipelajari, mengaktifkan siswa untuk memberikan tanggapan, terjadi umpan balik dan juga mendorong siswa untuk melakukan praktik-praktik dengan benar.

Oleh karena banyaknya manfaat yang diperoleh dari pemanfaatan media pembelajaran, maka guru sebagai sumber pembawa informasi bagi siswa hendaknya menyadari akan pentingnya penggunaan media dalam pembelajaran.

\section{Lectora Inspire sebagai Inovasi Pembelajaran}

Keberhasilan pembelajaran sangat dipengaruhi oleh kelengkapan sarana atau media yang digunakan karena semakin bervariasi media, pesan atau materi pembelajaran akan semakin optimal diterima siswa. Hal ini disebabkan adanya variasi dan keragaman modalitas belajar siswa bisa terakomodasi dari media yang variatif dalam pembelajaran. Misalnya, dalam satu kelas memiliki beberapa siswa yang beragam modalitas belajarnya. Sebagian siswa modalitas belajarnya lebih cenderung visual, sebagian siswa modalitas belajarnya cenderung audio, dan sisanya memiliki modalitas belajar kinestetik. Jika seorang guru dalam proses pembelajaran hanya menggunakan satu jenis media saja, maka pesan atau materi pembelajaran tidak bisa tersampaikan optimal karena faktor perbedaan modalitas belajar siswa.

Untuk itu, guru perlu mengkombinasikan berbagai jenis media dalam satu pembelajaran yaitu menggabungkan media berbasis visual, media berbasis audio, dan media berbasis kinestetik agar pesan bisa diserap semua siswa meski modalitasnya beragam. Penggabungan berbagai jenis media ini disebut dengan pembelajaran multimedia.

Dalam kamus Oxford-Advance Learner's Dictionary, disebutkan multimedia berarti involving several different methods of communication, yaitu melibatkan atau memasukkan berbagai metode berbeda dalam komunikasi. Dalam konteks pembelajaran, multimedia diartikan penggunaan berbagai jenis media dalam penyampaian pesan atau materi pembelajaran yang bertujuan agar pesan atau materi pembelajaran dapat diterima secara maksimal dan optimal oleh siswa yang memiliki modalitas berbeda. (Musfiqon, 2012,186).

Pembelajaran yang menggunakan teknologi informasi dan komunikasi atau menggunakan berbagai media disebut dengan media pembelajaran interaktif. Penggunaan media pembelajaran ini bertujuan untuk membantu para guru dalam penyampaian materi dan juga membantu siswa dalam memahami materi yang diajarkan. Selain itu, materi pelajaran dapat dimodifikasi menjadi lebih menarik dan mudah dipahami, serta suasana belajar yang menegangkan menjadi menyenangkan. Dengan menggunakan media pembelajaran interaktif, membantu guru menciptakan pola penyajian yang interaktif.

Berdasarkan definisi Hofstetter, bahwa multimedia interaktif adalah pemanfaatan komputer untuk menggabungkan teks, grafik, audio, gambar/ animasi, dan video menjadi satu kesatuan dengan link dan tool yang tepat sehingga memungkinkan pengguna dapat melakukan navigasi, berinteraksi, berkreasi, dan berkomunikasi. Dengan kita memanfaatkan multimedia dalam kegiatan belajar mengajar, proses pembelajaran menjadi bervariasi dan inovatif. Siswa akan tertarik, dapat mengurangi rasa bosan, dan 
akan timbul rasa penasaran. Oleh karena itu, perlu adanya inovasi khususnya dalam pembelajaran.

Inovasi adalah suatu ide, gagasan, praktik, atau benda yang diterima sebagai suatu hal yang baru oleh seseorang atau kelompok untuk diadopsi. Santoso S. Hamidjojo dikutip dari Abdulhak (2002) menjelaskan bahwa inovasi pendidikan sebagai "suatu perubahan yang baru dan secara kualitatif berbeda dari hal sebelumnya dan sengaja diusahakan untuk meningkatkan kemampuan demi mencapai tujuan tertentu, termasuk dalam bidang pendidikan”.

Inovasi pendidikan pada dasarnya merupakan suatu perubahan ataupun ide cemerlang di bidang pendidikan yang memuat hal baru berupa praktik-praktik pendidikan tertentu, produk dari suatu hasil olah pikir dan olah teknologi yang diterapkan melalui tahapan tertentu, untuk memecahkan persoalan pendidikan dan memperbaiki suatu keadaan pendidikan atau proses pendidikan tertentu yang terjadi di masyarakat.

Ada beberapa cara untuk membuat media pembelajaran interaktif. Berbagai software banyak ditawarkan dalam dunia pendidikan. Misalnya, aplikasi Ms. Power Point yang kita kenal untuk membuat media presentasi pembelajaran. Ms. Power Point selain bisa membuat media presentasi, dapat juga menyusun sebuah media evaluasi interaktif namun menggunakan Visual Basic, karena pada hakikatnya Ms. Power Point digunakan untuk media presentasi, meskipun dengan segala macam cara Ms. Power Point dapat digunakan untuk membuat media pembelajaran yang menarik. Bagi sebagian kalangan guru yang ingin serba instan, lectora inspire adalah aplikasi yang tepat, efektif, efisien untuk menjawab tantangan tersebut. Lectora inspire merupakan program aplikasi yang dapat digunakan untuk membuat presentasi maupun media pembelajaran.

Lectora inspire dikembangkan oleh Trivantis Corporation yang merupakan Authoring Tool untuk pengembangan konten e-learning. Pendirinya adalah Timothy D. Loudermilk di Cincinnati, Ohio, Amerika tahun 1999 (Muhammad Mas'ud, 2012:1). Pada tahun 2000, Lectora menjadi yang pertama sistem authoring AICC-bersertifikat di pasar. Lectora inspire dapat digunakan untuk menggabungkan flash, merekam video, menggabungkan gambar, dan screen capture.

Lectora inspire didesain khusus bagi pemula, sehingga keunggulan dari lectora inspire sangat mudah digunakan dalam pembuatan media pembelajaran dan dapat membuat materi uji atau evaluasi. Para guru yang tidak terlalu mahir mengoperasikan komputer, akan dengan mudah menggunakan aplikasi ini. Dengan menggunakan program aplikasi lectora inspire kita dapat menggunakannya dalam menyiapkan bahan ajar bagi siswa.

Media pembelajaran yang dikembangkan dengan menggunakan lectora inspire dapat dipublish secara online maupun offline. Siswa dapat belajar mandiri dengan media pembelajaran tersebut. Evaluasi yang terdapat dalam lectora inspire, dapat menampilkan feed back yang menunjukkan jawaban benar atau salah, dan skor yang bisa diketahui secara langsung. Sehingga memudahkan para guru untuk melakukan penilaian karena sudah otomatis muncul skor atau nilai.

Adapun manfaat yang kita temukan dari aplikasi Lectora inspire dalam pengembangan media pembelajaran interaktif, diantaranya sebagai berikut:

1. Guru dapat membuat dan menyajikan materi ajar dengan tanpa harus melakukan programming.

2. Guru dapat melakukan pengujian terhadap materi ajar yang diberikan, dalam berbagai macam bentuk test seperti pilihan ganda, benar/salah, mencocokan (mathcing), tarik dan tempatkan (drag and drop), isian singkat (fill in the blank), dan hot spot.

3. Guru/peserta didik dapat mengakses materi ajar/uji yang dibutuhkan baik secara offline maupun online.

4. Mampu menggunakan teks, suara, video, animasi dalam suatu kesatuan.

5. Mampu memvisualisasikan materi yang 


\section{abstrak.}

6. Membawa objek yang sangat besar atau berbahaya dalam lingkungan kelas.

7. Menampilkan objek yang tidak bisa dilihat oleh mata telanjang.

Selain itu, saat kita menginstal lectora inspire, ada beberapa software bawaan dari lectora inspire yang terinstal, seperti flypaper, camtasia, dan snagit. Flypaper adalah software yang digunakan untuk menggabungkan gambar, video, flash, animasi transisi, dan game memory. Camtasia dapat digunakan untuk mengedit video. Sedangkan Snagit digunakan untuk mengcapture gambar yang ada di layar monitor dan dapat juga untuk menggabungkan beberapa gambar menjadi satu.

\section{Pengembangan Media Lectora Inspire di Madarasah}

Produk lectora inspire dikenalkan di lingkugan madrasah dengan cara memberikan pelatihan kepada guru-guru tentang bagaimana mengembangkan media pembelajaran yang interaktif. Metode yang dilakukan untuk mengembangkan media pembelajaran interaktif dengan lectora inspire ini tahapannya meliputi mengumpulkan informasi, perencaaan, pelaksanaan, presentasi dan refleksi yang dijabarkan sebagai berikut:

\section{Tahap Mengumpulkan Informasi}

Pengumpulan informasi sangat penting untuk mengetahui kebutuhan dari masyarakat pemakai terhadap produk yang ingin dikembangkan melalui penelitian dan pengembangan. Pengumpulan informasi bisa dilakukan dengan pengukuran kebutuhan, studi literatur, penelitian dalam skala kecil, dan pertimbangan-pertimbangan dari segi nilai (Nana Syaodih Sukmadinata, 2009:169)

Pada tahap berikutnya, yaitu melakukan observasi ke MIM Jagalan dan MIM Jumoyo. Kegiatan ini bertujuan untuk mengetahui pelaksanaan pembelajaran di kelas, metode pembelajaran yang digunakan, serta permasalahan yang dihadapi guru dan siswa dalam proses pembelajaran. Selanjutnya, melakukan studi literatur yang berkaitan dengan permasalahan yang dikaji dan mengumpulkan informasi yang terkait dengan media pembelajaran interaktif dan lectora inspire.

2. Tahap Perencanaan

Pada tahap ini, langkah yang dilakukan adalah rencana sebelum mengembangkan media pembelajaran lectora inspire, meliputi:

a. Analisis Kurikulum

Pengembangan media pembelajaran interaktif harus di dasarkan pada kurikulum MI yang meliputi standar kompetensi, kompetensi dasar, dan indikator pencapaian hasil belajar.

b. Peta konsep sebagai rancangan pembelajaran yang akan disajikan dalam bentuk multimedia, contoh sebagai berikut.

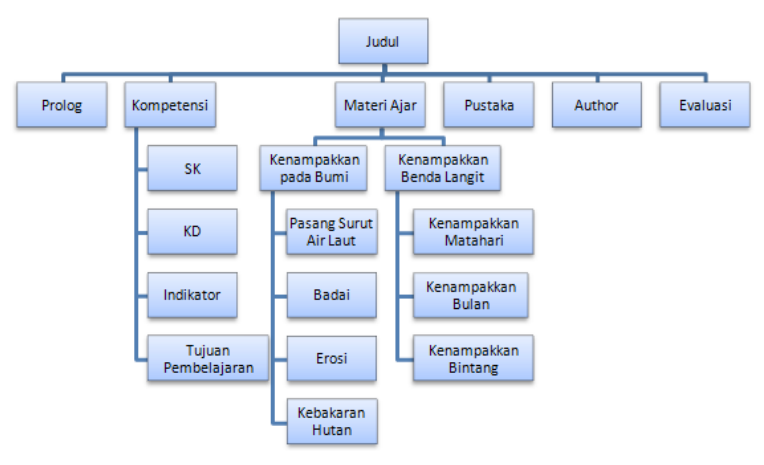

Gambar Diagram Peta Konsep

c. Membuat storyboard

Storyboard merupakan visualisasi ide yang akan dibangun, sehingga dapat memberikan gambaran dari aplikasi yang akan dihasilkan.

Contoh sebagai berikut.

\begin{tabular}{|l|l|}
\hline Multimedia Pembelajaran Interaktif \\
\hline Prolog & Perubahan Kenampakkan pada Bumi \\
Kompetensi & dan Benda Langit \\
Materi Ajar & \\
Pustaka & IPA Kelas IV \\
Author & Oleh: \\
Evaluasi & \\
\hline
\end{tabular}




\begin{tabular}{|l|l|}
\hline & \\
\hline Prolog & Chapter Prolog \\
Kompetensi & Gambaran tentang materi yang ingin \\
Materi Ajar & disampaikan \\
Pustaka & \\
Author & \\
Evaluasi & \\
\hline
\end{tabular}

Gambar. Contoh Membuat Storyboard

d. Membuat jabaran materi, yaitu menyiapkan materi pelajaran yang sesuai dengan standar konpetensi dan kompetensi dasar.

e. Membuat bank data berupa gambar, artikel/tulisan, animasi, audio, dan video yang akan digunakan dalam mengembangkan media pembelajaran.

f. Menyiapkan soal dan jawabannya untuk memudahkan dalam membuat evaluasi setelah pembelajaran.

3. Tahap Pelaksanaan

Pada tahap ini adalah memberikan pelatihan berupa pengembangan media pembelajaran interaktif dengan lectora inspire. Namun sebelum ke pelatihan, memberikan brain storming terlebih dahulu mengenai media pembelajaran interaktif dan demo tampilan lectora inspire.

Pada saat pelatihan, mula-mula para guru menginstal aplikasi lectora inspire. Kemudian mengikuti panduan dari instruktur maupun membaca dari modul yang telah diberikan. Para guru diberi kebebasan untuk bisa berkreasi membuat desain media pembelajaran lebih menarik. Ketika guru melaksanakan pelatihan, kami tim pengabdian dan para mahasiswa sebagai fasilitator melakukan pengamatan kepada para guru untuk selalu siap sedia membantu apabila ada guru yang belum paham.

Beberapa hal yang ditekankan dalam pelatihan ini, guru dapat membuat media pembelajaran interaktif dengan membuat materi pelajaran, mendesain dengan gambar, suara, video; membuat evaluasi yang dapat memunculkan skoring/nilai, dan mem-publish. Berikut contoh tampilan hasil pengembangan media pembelajaran interaktif dengan lectora inspire.

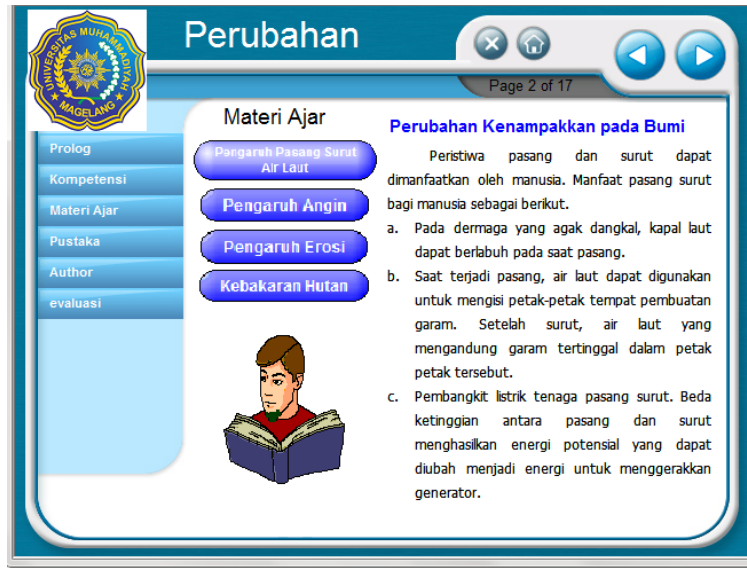

Gambar media pembelajaran interaktif yang menampilkan materi

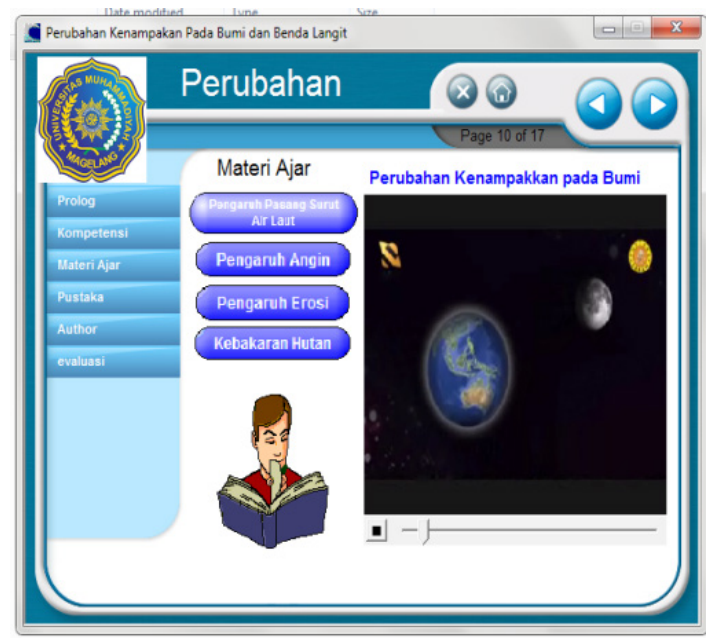

Gamba media pembelajaran interaktif yang menampilkan animasi dan video

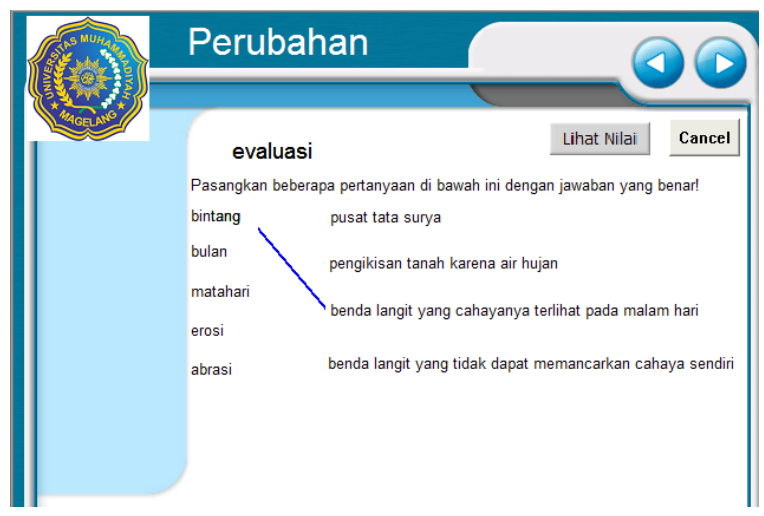

Gambar media pembelajaran interaktif yang menampilkan evaluasi

4. Tahap Presentasi dan Refleksi

Setelah para guru selesai melaksanakan pelatihan, tahap selanjutnya adalah 
mempresentasikan hasil media pembelajaran yang telah dibuat oleh guru. Dari presentasi yang ditampilkan para guru, kami memberikan apresisasi dan saran masukan.

\section{Simpulan}

Dalam bidang pendidikan, inovasi adalah hal yang mutlak dilakukan, karena tanpa inovasi akan terjadi ketertinggalan pada dunia pendidikan kemudian akan berimbas pada elemen-elemen kehidupan yang lain seperti politik, ekonomi, sosial, dan lain-lain. Guru dituntut untuk dapat mengembangkan keterampilan membuat media pembelajaran, apalagi media tersebut belum tersedia di madrasah. Untuk itu, guru harus memiliki pengetahuan dan pemahamaan yang cukup tentang media pembelajaran. Di sinilah kami memberikan pelatihan kepada para guru, untuk mampu menciptakan pembelajaran yang inovatif dan lebih menarik yaitu dengan membuat media pembelajaran interaktif dengan lectora inspire. Pelatihan pengembangan media pembelajaran interaktif dengan lectora inspire ini bertujuan untuk meningkatkan mutu madrasah, mengembangkan media pembelajaran interaktif, dan meningkatkan kreativitas guru, sehingga menghasikan produk berupa media pembelajaran interaktif yang dapat digunakan guru maupun siswa yang ingin belajar mandiri. Metode pelaksanaan dalam ipteks pengabdian masyarakat ini tahapannya meliputi mengumpulkan informasi, perencaaan, pelaksanaan, presentasi dan refleksi.

\section{Referensi}

Abdulhak, Ishak, Pelaksanaan Inovasi Pendidikan dalam Pengantar Pendidikan. Jakarta : Pusat Penerbitan Universitas Terbuka, 2000.

Azhar Arsyad, Media Pembelajaran, Jakarta: PT Raja Grafindo Persada, 2007.

Mas'ud, Muhammad, Membuat Multimedia Pembelajaran dengan Lectora, Yogyakarta:Shonif, 2012

Musfiqon, Pengembangan Media \& Sumber Pembelajaran, Jakarta: PT Prestasi Pustakaraya, 2012

Sukmadinata, Nana Syaodih, Metode Penelitian Pendidikan, Bandung: PT Rosdakarya, 2012.

Sutirman, Media \& Model-Model Pembelajaran Inovatif, Yogyakarta: Graha Ilmu, 2013.

Trianto, Mendesain Model Pembelajaran Inovatif-Progresif. Jakarta: Kencana, 2009. 